\title{
30 Policy options for cropping systems diversification in Southern Africa
}

\author{
Giuseppe Maggio and Nicholas J. Sitko
}

\section{Introduction}

Crop diversification cuts across the economic development and climate change adaptation policy agenda of many countries in sub-Saharan Africa (SSA). For example, about a third of the SSA countries that have submitted a Nationally Determined Contribution plan to the United Nations Framework Convention on Climate Change (UNFCCC) list diversification among their key climate adaptation objectives (UNFCCC, 2019). Crop diversification is seen as a mechanism to increase agricultural productivity and production value, and thus to sustain food security of smallholders and to build resilience to adverse weather and market price fluctuations.

Despite the recognition diversification's central role for the future of agricultural in SSA, diversification levels are quite limited in many smallholder systems in the region. Moreover, adoption of more diverse cropping systems is often hindered by government policy actions that reduce incentives for appropriate crop diversification pathways. In several southern African countries, for example, input and output subsidies often target staple food crops and may inadvertently push farmers to adopt lowly diversified cropping systems or of cropping systems with poor compatible with prevailing agro-ecological conditions.

The attributes of the crops composing a given cropping system, as well as their interactive effect, are the principal determinants of the productivity, the production value and the resilience of the cropping system to external shocks, such as drought, flood or fluctuation in prices. When farmers evaluate the inclusion of a given crop within their cropping system, they often must weigh the advantages and drawbacks that the crop will bring to the system, conditional on the expected weather and agro-ecological condition, production cost and marketability. For example, the inclusion of staple crops that are tolerant to high temperatures, such as cassava, may help a farmer to ensure their production against the occurrence of droughts. However, due to its limited commercial value the inclusion of this crop may reduce the overall value of a farmer's production (Schlenker and Lobell, 2010). Intercropping with legume crops, such as pigeon peas, beans and groundnuts, can help improve soil quality and nutrient content, thus improving the performance of other crops in the system, 
but their inclusion may also be conditioned on prevailing market factors for these crops (Kerr et al., 2007; Sileshi et al., 2008). Others, such as cash crops, can bring higher returns from their marketization, but their price suffer of high interannual volatility, impeding a correct prediction of the final profit from their cultivation (Chapoto et al., 2013). Unpacking the potential benefits and risks associated with the inclusion of particular crops into a cropping system is critical for developing appropriate crop diversification policy strategies.

Focusing on the southern African countries of Malawi, Mozambique and Zambia, this chapter empirically examines crop systems diversification drivers and impacts in order to provide policymakers with insights into viable strategies to enhance smallholder productivity and build resilience. This is done using nationally representative household surveys that capture information at an individual-, field- and community-level for multiple agricultural seasons (IAI, 2015; IHPS, 2013; RALS, 2015). The analysis focuses on maize smallholder farmers, as maize remains the dominant staple food in these countries, and measures the effect of diversification in terms of maize productivity and crop income volatility.

This capture moves beyond standard measures of diversification used in economic literature, which rely on abstract indicators such as the Gini coefficient or the Margalef index, which do not provide insights into the underlying crops farmers include in their systems (Arslan et al., 2018). To address this weakness, the chapter considers seven possible cropping systems adopted by the farmers, based on combinations of four categories of crops: dominate staple (maize), alternative staple (e.g., cassava, millet, sweet potato), legumes (e.g., groundnuts, pigeon pea, beans) and cash crops (e.g., cotton, sunflowers, tobacco).

\section{The geography of cropping systems}

Figures 30.1 displays the distribution of the dominant cropping systems in Malawi, Mozambique and Zambia, at the district level, defined in terms of the cropping systems with the greatest share of cultivated land for that district. Note that the maize-legume-staple system is most widely adopted in Mozambique and Zambia, while in Malawi the majority of the area is under maize monocropping and maize-legume. In all cases, the dominant cropping systems are primarily subsistence oriented.

In general, spatial clustering of cropping systems is evident within each country, indicating internal spatial spillovers in adoption, which is likely associated with variations in infrastructural and market development. In eastern Zambia, for example, the dominant system is the maize-legume-cash crop system, which is associated with private investments in legume and cotton markets in the region. This system is also dominant across the border in Mozambique and may reflect market spillovers between the two countries. This is likely due to the limited infrastructural connectivity in this region of Mozambique, which therefore favours cross-border trade over domestic markets for farmers close to 


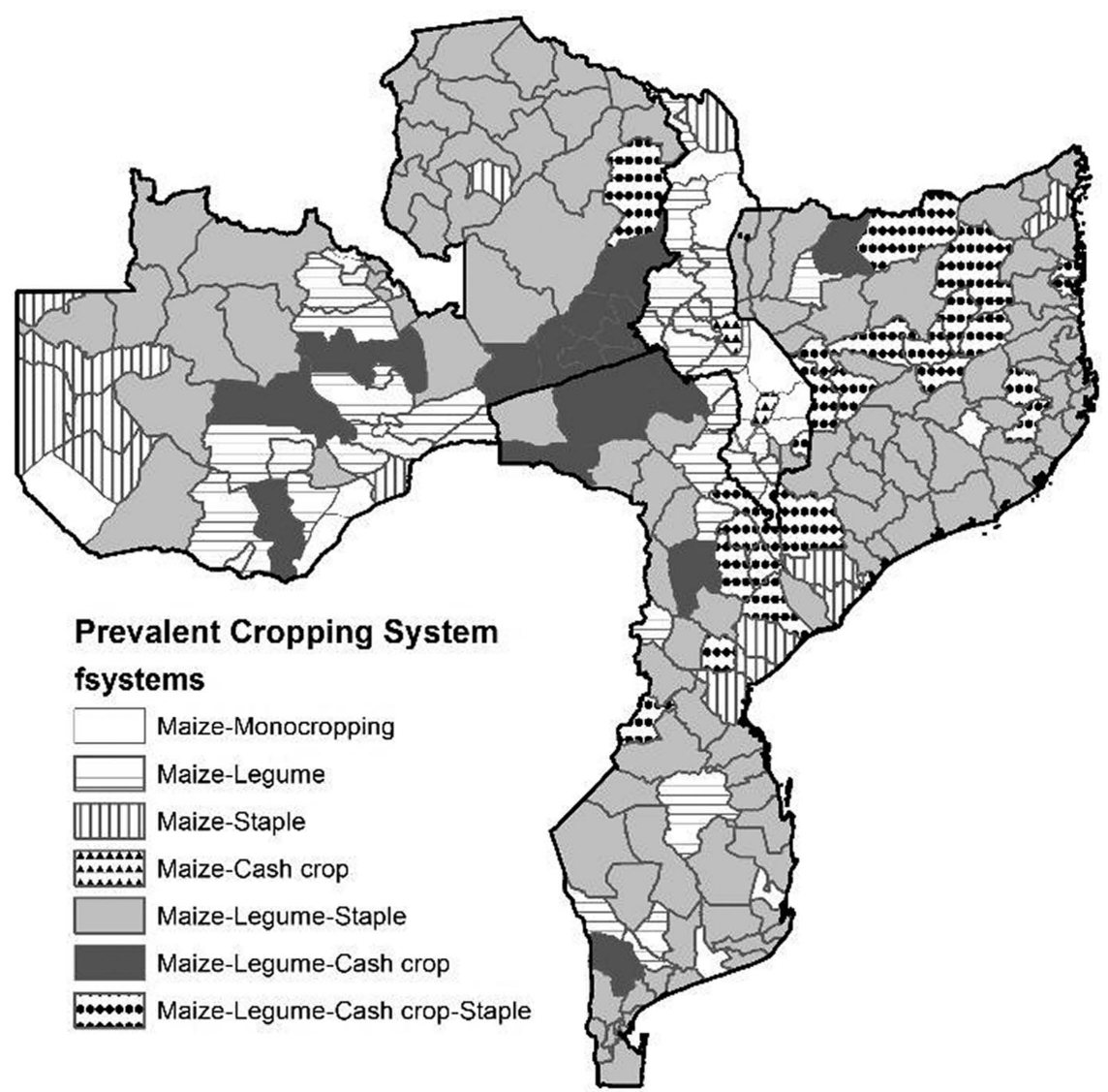

Figure 30.1 Prevalent cropping system at the district level

Note: prevalent cropping system is the one with the highest relative share of land cultivated at the district level

Source: Maggio et al., 2018

the border. This market spillover is not, however, apparent between Malawi and Zambia where cross border trade is more restricted.

\section{Understanding the limitations of dominant cropping systems}

Several country-specific limitations are apparent in the dominant cropping systems and help explain the limited adoption of more market-oriented systems. In Malawi, the dominant systems are maize monocropping and maize-legume, 
suggesting a low general level of diversification. In this country, socioeconomic and institutional factors appear to disincentivize diversification. Diversification in Malawi is most prevalent among larger and wealthier farms, as these farmers have greater physical and financial resources to incorporate additional crops into their systems. For most farmers in Malawi, where average land holdings are less than 1 hectare, maize production is often prioritized to meet household food security requirements. At institutional level, the farmers appear to diversify only they have access to functional, competitive and stable input and output markets. The lack of stability in prices may disincentive diversification towards certain crops. For example, the low adoption of alternative staple and cash crops may be linked to their price volatility compared to legumes. As shown in Table 30.1, between 2010 and 2014 the prices of cassava, cotton and sorghum prices were 14, 15 and $74 \%$ more volatile than groundnut prices.

In Mozambique, $47 \%$ of the households grows systems of three crops, including maize, with staples such as cassava/sorghum and at least a legume, such as beans and pigeon pea. Despite being highly diversified, this system is associated to low adoption of inorganic fertilizer and low crop income gains compared to monocropping (see Table 30.2). The reason behind the diffusion of this system relies on its resilience to weather fluctuations, especially to drought shocks. However, it would be important to find solutions to help farmers moving

Table 30.1 Groundnut prices are less volatile than alternative staples and cash crops in Malawi

\begin{tabular}{lclc}
\hline Crop & Price growth rate $(2010-2014)$ & Price volatility (PV) & PV relative to Groundnuts \\
\hline Cassava & 0.29 & 0.16 & $14 \%$ \\
Cotton & -0.18 & 0.16 & $15 \%$ \\
Groundnuts & 0.27 & 0.14 & - \\
Sorghum & 0.22 & 0.24 & $74 \%$ \\
\hline
\end{tabular}

Source: Authors own elaboration using FAOSTAT

Table 30.2 Adoption of fertilizer and contribution in income of the cropping systems in Mozambique

\begin{tabular}{lrccc}
\hline & $\begin{array}{c}\text { Share of } \\
\text { Adopters }\end{array}$ & $\begin{array}{l}\text { Inorganic } \\
\text { fertilizer } \\
\text { adopters }\end{array}$ & $\begin{array}{l}\text { Crop Income } \\
\text { (US\$ 2010) }\end{array}$ & $\begin{array}{l}\text { Change in Crop } \\
\text { Income compared } \\
\text { to MM }\end{array}$ \\
\hline Maize monocropping (MM) & $6 \%$ & $4 \%$ & 220 & - \\
Maize-Legume & $19 \%$ & $4 \%$ & 397 & $180 \%$ \\
Maize-Staple & $9 \%$ & $2 \%$ & 448 & $113 \%$ \\
Maize-Cash Crops & $2 \%$ & $23 \%$ & 741 & $165 \%$ \\
Maize-Legume-Staple & $47 \%$ & $3 \%$ & 361 & $49 \%$ \\
Maize-Legume-Cash Crops & $5 \%$ & $28 \%$ & 1100 & $305 \%$ \\
Maize-Legume-Cash Crops-Staple & $12 \%$ & $10 \%$ & 688 & $63 \%$ \\
\hline
\end{tabular}

Source: Authors own elaboration using the survey data 
from this subsistence-oriented system towards the adoption of more marketoriented systems, such as the maize-legume-cash crops system. Indeed, adopters of cropping systems including cash crops show substantial gains in terms of crop income and resilience, compared both to maize monocropping and to maizelegume-alternative staple systems.

In Zambia, about half of the farmer population relies on systems with three or more crops. However, there is an apparent geographic disconnection between levels of cropping system diversification and the frequency of climatic risks that farmers experience. In particular, in the north and northwest of the country the dominant cropping system is a three-crop system comprising legumes and cassava. This system would be particularly well suited for drought prone areas, but the zones where it is adopted most receive substantially more rainfall than the rest of the country. Maize monocropping and two-crop systems, in contrast, prevail in the south of the country, where both land fragmentation and rainfall variability are higher. As shown in Figure 30.2, higher rainfall risks, measured as quartiles in historical volatility of rainfall, is strongly associated with lower level of diversification. In particular, the share of farmers adopting one- or two-crop systems is higher in high risk areas and lower in low risk areas (Figure 30.2). Addressing this spatial disconnect in cropping system diversification may be an important avenue for improving climate resilience among Zambian smallholders.

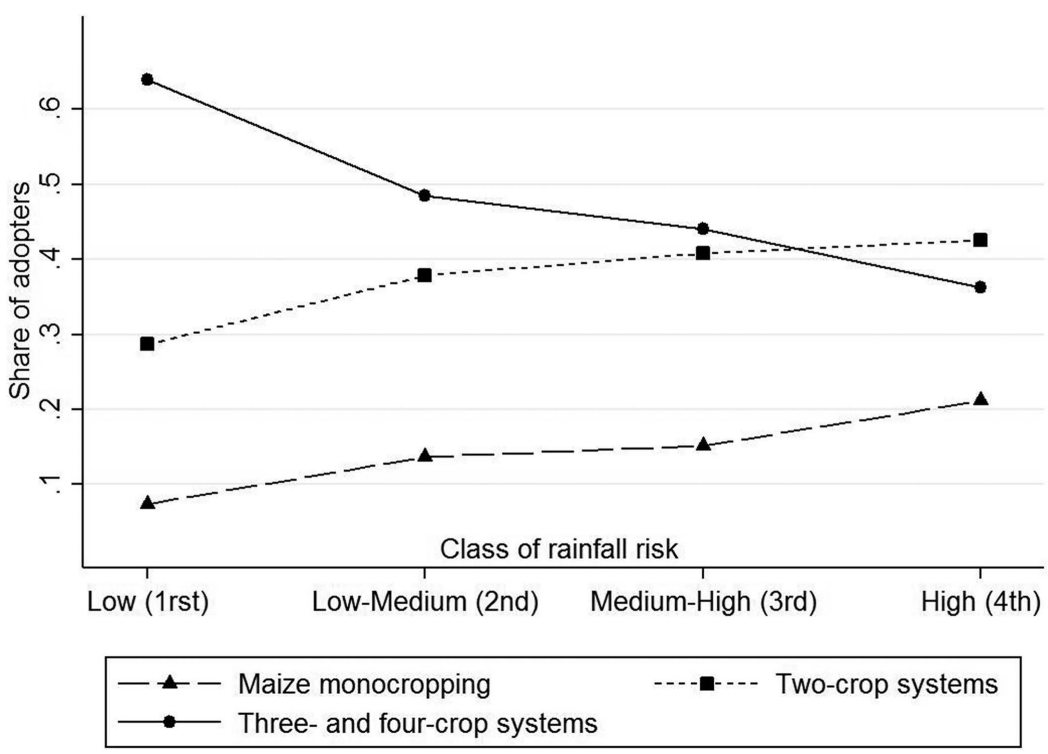

Figure 30.2 Farmers are adopting more vulnerable systems for higher classes of rainfall risk in Zambia

Source: Own representation using RALS 2015 data 


\section{Drivers and impact of cropping systems diversification}

In general, three factors appear to influence the adoption of more diversified systems across the three countries. First, private output market development is a key driver of adopting more diverse and commercialized cropping systems. This is partially driven by the impact of transactions costs on seed prices, including maize seed prices. Given scarce resources, farmers often prioritize purchasing staple food seeds before investing in other inputs. Contrary to expectations, when maize seed prices increase the probability of diversification often declines. For example, in Malawi, an increase of maize seed prices by 2.1 US $\$$ decreases by the probability of adopting a four-crop system by $2 \%$.

Second, the presence of parastatal marketing boards appears to affect farmers' decisions about diversification. The parastatal marketing boards operate in Malawi and Zambia and typically focus on purchasing maize from individual farmers and cooperatives at pan-territorial price that typically exceeds prevailing market prices. This elevated market price acts as a disincentive to diversification. In Zambia, for example, as the distance between farmers and buying depots for the Food Reserve Agency increase, the probability of adopting more diverse three- and four-crop systems increases significantly.

Finally, larger land holdings and household wealth status are found to be significant drivers of diversification in all cases. These better-off households are able to manage the costs and risks of experimenting with new cropping systems and integrating a larger range of food and nonfood crops into their farm systems.

The magnitude of the impact of cropping system diversification on maize productivity varies across countries and cropping systems, but several commonalities emerge from the analysis. All the cropping systems exhibit higher levels of maize productivity compared to maize monocropping when controlling for all other factors. The only exception of is for systems comprised of maize with an alternative staple crop. This is likely because alternative staple crops do not confer agronomic benefits to maize, as legumes typically do, nor do they typically provide commercialization options, like cash crops, which would support farmers to intensify production with capital inputs. The adoption of three- and four-crop systems in general results in higher maize yields than maize monocropping. In Malawi, for example, farmers adopting three-crop systems based on maize, legumes and a third crop (cash or alternative staple), are likely to increase their maize yield of between 15 and 37 compared to monocropping.

In terms of the resilience of cropping systems, the empirical results highlight important differences between the seven cropping systems across the three countries. This heterogeneity is likely due to variations in the market conditions for the crops composing the systems within each country and differences in agro-ecological characteristics. For example, in Malawi, only the maizelegume system appears to reduce significantly farmers' crop income volatility, while adopters of all the other cropping systems experience levels of income volatility that are similar to those of maize monocropping. In Mozambique, 
only systems based on three crops, such as maize-legume-cash crops, are effective in reducing crop income volatility. In Zambia, all the cropping systems appear to reduce volatility in crop income compared to maize monocropping, with an increasing effect for more diversified cropping systems.

\section{Policy conclusions for cropping system diversification}

What actions can policymakers undertake to support the adoption of more diversified and resilient cropping systems? The results from the analysis suggest that policymakers should prioritize three areas of intervention in their countries.

\section{Policymakers will need to incentivize investments in the private input and output markets}

A set of direct and indirect policies may help the development of such markets and improve the level of diversification of the agricultural sector. For example, diversification may be enhanced through the promotion of stable macroeconomic conditions and predictable trade policy, which may induce private investments in agricultural markets. If necessary, trade restrictions on staple foods, such as maize, should be applied in predictable ways and supplemented with import support measures.

Implementing policies that favour competition in the seed sector may help seeds multiplication and, in the medium term, crop system diversification. The three countries differ in their level of seed market development. Zambia, for example, has a relatively more advanced seed market compared to Malawi and Mozambique, and different public and private actors participate to its sector under the umbrella of the Zambia Agriculture Research Institute (ZARI). Malawi and Mozambique observe a low number of seed breeders and foundation seeds producers, with a consequent low number of seeds traded along all the value chain. This is often associated with the low prices set for the foundation seeds produced by the public institutions. It is necessary therefore to create incentives through the creation of public-private partnerships along all the seed value chains. In certain contexts, a stricter enforcement of the laws defending breeders' rights and supportive legislation for small-scale and community-based breeders may incentivize investments in the sector.

\section{Policymakers may need to rethink public intervention in markets to achieve crop diversification objective}

It is necessary to reconsider interventions into output markets when these generate distortive effects to diversification, especially in periods of normal or above normal production. For example, floor prices may be relaxed when international prices are higher than internal ones to incentivize trading and investment in cash crops. Public market boards selling large quantities of maize 
in certain regions may inadvertently reduce the price taken by local producers and thus reduce the possibility of investment into alternative staples, legumes and cash crops during the next agricultural season. Any policy supporting the development of contract farming sectors should include, among its objectives, a minimum level of diversification at the farm level, so to improve smallholders' economic efficiency and economic resilience to unexpected market and weather shocks.

Finally, ongoing reforms to support programmes, such as the Farm Input Subsidy Programme (FISP) in Malawi, should consider crop diversification as one of their key objectives. Amendments may include more flexibility in the types of seeds, improvement in the quality of seeds and promotion of seeds compatible with the local agro-ecological conditions of the zone of distribution.

\section{Policies to improve land tenure security are important for diversification}

Land acquisition by urban resident and large agribusiness firms are widespread in the region (Sitko and Jayne, 2014; Jayne et al., 2016).

To guarantee land access to smallholders, policymakers may consider policies regulating the land acquisition from large agribusiness or companies outside the farming sector, while supporting mortgage and micro-credit finance for the most productive smallholders. Land constrains are particularly binding in urban and peri-urban areas, where farmers operate in zones with high population densities and high land fragmentation (Sitko and Chamberlin, 2016). To facilitate land consolidation in those areas, policymakers may consider supporting the network of public transportation to the countryside of the most densely populated cities. An improved transportation network may help farming households in accessing cheaper land and may help decrease the price of land in the peri-urban areas. Finally, policymakers may design simplified land registration procedures and provide support to help land registration of the households still residing on statutory land, who often lack the knowledge of how to secure their land rights.

\section{References}

Arslan, A., Cavatassi, R., Alfani, F., Mccarthy, N., Lipper, L. and Kokwe, M. (2018) Diversification under climate variability as part of a CSA strategy in rural Zambia. The Journal of Development Studies, 54(3), 457-480.

Chapoto, A., Haggblade, S., Hichaambwa, M., Kabwe, S., Longabaugh, S., Sitko, N. and Tschirley, D. (2013) Institutional models for accelerating agricultural commercialization: Evidence from maize, cotton and horticulture. No. 154940. Michigan State University, Department of Agricultural. Food, and Resource Economics.

IAI. (2015) Inquérito Agricola Integrado. Ministéiro da Agricultura e Segurança Alimentar. Maputo, Moçambique: República de Moçambique.

IHPS. (2013) Malawi Integrated Household Panel Survey. Lilongwe, Malawi: Government of Malawi. 
Jayne, T.S., Chamberlin, J., Sitko, N., Muyanga, M., Yeboah, F.K., Nkonde, C., Aneeuw, W., Traub, L., Chapoto, A. and Kachule, R. (2016) Africa's changing farmland ownership: The rise of the emergent investor farmer. Agricultural Economics, 47(S1), 197-214.

Kerr, R. B., Snapp, S., Chirwa, M., Shumba, L. and Msachi, R. (2007) Participatory research on legume diversification with Malawian smallholder farmers for improved human nutrition and soil fertility. Experimental Agriculture, 43(4), 437-453.

Maggio, G., Sitko, N. J. and Ignaciuk, A. (2018) Cropping System Diversification in Eastern and Southern Africa: Identifying Policy Options to Enhance Productivity and Build Resilience (No. 288953). Food and Agriculture Organization of the United Nations, Agricultural Development Economics Division (ESA).

RALS. (2015) Agricultural Livelihoods Survey. Lusaka, Zambia: Government of Zambia.

Schlenker, W. and Lobell, D. B. (2010) Robust negative impacts of climate change on African agriculture. Environmental Research Letters, 5(1), 014010.

Sileshi, G., Akinnifesi, F. K., Ajayi, O. C. and Place, F. (2008) Meta-analysis of maize yield response to woody and herbaceous legumes in sub-Saharan Africa. Plant and Soil, 307 (1-2), 1-19.

Sitko, N. J. and Chamberlin, J. (2016) The geography of Zambia's customary land: Assessing the prospects for smallholder development. Land Use Policy, 55, 49-60.

Sitko, N. J. and Jayne, T. S. (2014) Structural transformation or elite land capture? The growth of "emergent" farmers in Zambia. Food Policy, 48, 194-202.

United Nations Framework Convention on Climate Change (2019) Nationally Determined Contribution Registry, Country Pages. https://www4.unfccc.int/sites/NDCStaging/Pages/ All.aspx. 